Pacific Journal of Mathematic 


\title{
MEASURES AS FUNCTIONALS ON UNIFORMLY CONTINUOUS FUNCTIONS
}

\author{
JAN K. PACHL
}

The space $\mathfrak{M}_{t}$ of bounded Radon measures on a complete metric space is studied in duality with the space $\mathscr{U}_{b}$ of bounded uniformly continuous functions. The weak topology has reasonable properties: the space $\mathfrak{M}_{t}$ is $\mathscr{U}_{b}$-weakly sequentially complete, and every $\mathscr{U}_{b}$-weakly compact subset of $\mathfrak{M}_{t}$ is pointwise equicontinuous on the set of 1-Lipschitz functions.

1. Introduction. Let $(X, d)$ be a complete metric space and $\mathfrak{M}_{t}(X)$ the space of (bounded) Radon (=tight) measures on $X$. This space is usually studied in duality with the space $\mathscr{C}_{b}(X)$ of bounded continuous functions on $X$. It is known that the weak topology $w\left(\mathfrak{M}_{t}(X), \mathscr{C}_{b}(X)\right)$ is sequentially complete, and there is a useful criterion (Prohorov's condition) for $w\left(\mathfrak{M}_{t}, \mathscr{C}_{b}\right)$-compactness [11].

In this paper we turn to the space $\mathscr{Q}_{b}(X)$ of bounded uniformly continuous functions on $X$ and to the weak topology $w\left(\mathfrak{M}_{t}(X), \mathscr{U}_{b}(X)\right)$. The topologies $w\left(\mathfrak{M}_{t}, \mathscr{C}_{b}\right)$ and $w\left(\mathfrak{M}_{t}, \mathscr{U}_{b}\right)$ coincide on the positive cone $\mathfrak{M}_{t}^{+}$; thus our results say nothing new about positive measures. Obviously, the two topologies differ (on $\mathfrak{M}_{t}$ ) whenever $\mathscr{C}_{b} \neq \mathscr{C}_{b}$.

The main results are: (A) the topology $w\left(\mathfrak{M}_{t}, \mathscr{U}_{b}\right)$ is sequentially complete, and (B) a norm-bounded subset of $\mathfrak{M}_{t}$ is relatively $w\left(\mathfrak{M}_{t}, \mathscr{C}_{b}\right)$ compact if and only if its restriction to the set

$$
\operatorname{Lip}(1)=\{f: X \rightarrow R \mid\|f\| \leqq 1 \text { and }|f(x)-f(y)| \leqq d(x, y) \text { for } x, y \in X\}
$$

is equicontinuous in the compact-open topology.

The topology of uniform convergence on Lip (1) was discussed by Dudley [3]. Here we improve some of Dudley's results. For example, Theorem 6 in [3] says, in the present setup, that $\mu_{n} \rightarrow \mu$ uniformly on Lip (1) whenever $\mu \in \mathfrak{M}_{t}, \mu_{n} \in \mathfrak{M}_{t}$ for $n=1,2, \cdots$, and $\mu_{n}(f) \rightarrow \mu(f)$ for each $f \in \mathscr{C}_{b}(X)$. Here we obtain the same conclusion, assuming only that $\mu_{n}(f) \rightarrow \mu(f)$ for each $f \in \mathscr{U}_{b}(X)$.

A reasonable generalization is to allow $X$ to be an arbitrary uniform space and replace $\mathfrak{M}_{t}$ by the space $\mathfrak{M}_{u}(X)$ of uniform measures on $X$ (see [4] and the references therein). The results extend to the space $\mathfrak{M}_{u}(X)$, as well as to the space $\mathfrak{M}_{F}(X)$ of free uniform measures. Several previously studied spaces of measures can be described as $\mathfrak{M}_{u}$ or $\mathfrak{M}_{F}$-see [5], [8]. To cover both $\mathfrak{M}_{u}$ and $\mathfrak{M}_{F}$, in $\S 2$ we employ sets of Lipschitz functions more general than $\operatorname{Lip}(1)$.

As in similar situations studied before (e.g., [1], [10]), the goal 
of the construction is to pass from $\mathfrak{M}_{t}(X)$ to the space $l^{1}=\mathfrak{M}_{t}(N)$. It should be noted, however, that the approach through partitions of unity ([10], [12]) seems to be barred, in view of the theorem by Zahradník [13] which says that there are metric spaces without a sufficient supply of $l^{1}$-continuous partitions of unity.

An earlier version of this paper was announced in [9].

2. Construction. The property of Radon measures we are chiefly interested in is their continuity on $\operatorname{Lip}(1)$ (or on more general sets of Lipschitz functions). In Lip(1), the compact-open topology agrees with the topology of pointwise convergence, and the latter will be easier to deal with.

Throughout this section, $(X, d)$ will be metric space and $h$ a Lipschitz function on $X$; that is, $h$ maps $X$ into the field $R$ of real numbers and

$$
|h(x)-h(y)| \leqq d(x, y)
$$

for $x, y \in X$. Put

$$
\operatorname{Lip}(h)=\{f: X \rightarrow R|| f \mid \leqq h \text { and }|f(x)-f(y)| \leqq d(x, y) \text { for } x, y \in X\},
$$

and denote by $U$ the linear space spanned by $\operatorname{Lip}(h)$. Endow $U$ with the topology of pointwise convergence (i.e., $U$ is a topological subspace of $R^{X}$ ) and denote by $\mathfrak{M}$ the space of the linear forms on $U$ whose restrictions to $\operatorname{Lip}(h) \subset U$ are continuous. Endow $\mathfrak{M}$ with the norm

$$
\|\mu\|_{d, h}=\sup \{|\mu(f)| \mid f \in \operatorname{Lip}(h)\} .
$$

Needless to say, both $U$ and $\mathfrak{M}$ depend on $h$.

As Lip $(h)$ is compact, the Ascoli theorem ([6], Ch. 7, Th. 17) gives the following precompactness criterion.

LemMa 2.1. A subset of $\mathfrak{M}$ is $\|\cdot\|_{d, h}$-precompact if and only if it is equicontinuous on $\operatorname{Lip}(h)$.

The main idea in the proof of the following lemma is to choose as small functions in $\operatorname{Lip}(h)$ as possible and then use the fact that they cannot be made smaller. This is why it will be convenient to work with (nonnegative) functions in Lip $(h)$ which are "small far from a finite set": say that $f \in \operatorname{Sm}(h)$ if and only if there is a nonempty finite set $F(f) \subset X$ such that

$$
f=\inf \{g \in \operatorname{Lip}(h) \mid g \geqq 0 \text { and } g(y) \geqq f(y) \text { for every } y \in F(f)\} .
$$

Obviously $\operatorname{Sm}(h) \subset \operatorname{Lip}(h)$. The set $F(f)$ is not unique (in fact, the 
equality remains true when $F(f)$ is replaced by any larger set); we fix arbitrarily, for each $f \in \operatorname{Sm}(h)$, a nonempty finite set $F(f)$ satisfying the above equality.

Notice that each $f \in \operatorname{Sm}(h)$ can be described explicitly in terms of $d$ and $F(f)$ :

$$
f(x)=\max \left\{(f(y)-d(y, x))^{+} \mid y \in F(f)\right\} .
$$

Note also that $\operatorname{Sm}(h)$ is pointwise dense in $\operatorname{Lip}^{+}(h)=\{f \in \operatorname{Lip}(h) \mid f \geqq 0\}$; indeed, every nonnegative function in $\operatorname{Lip}(h)$ is the supremum of a subset of $\operatorname{Sm}(h)$.

The system of finite subsets of $X$ is denoted by Fin $(X)$.

When $Y \subset X$ and $f$ is a function on $X$, write

$$
\|f\|_{Y}=\sup \{|f(y)| \mid y \in Y\}
$$

and $\|f\|=\|f\|_{X}$.

LEMma 2.2. Let $M \subset \mathfrak{M}$ and suppose that there is a $t>0$ such that $|\mu(f)| \leqq t\|f\|$ for any $\mu \in M$ and any bounded $f \in U$. If $M$ is not $\|\cdot\|_{d, h}-$ precompact then there are: an $\varepsilon>0, g_{k} \in \operatorname{Sm}(h)$ and $\mu_{k} \in M, k=1,2, \cdots$, such that for each $k$ we have

$1^{0} .\left|\mu_{k}\left(g_{k}\right)\right|>2 \varepsilon$,

$2^{0} . \quad\left|\mu_{j}\left(g_{k}\right)\right| \leqq \varepsilon$ for $j<k$, and

$3^{0} . \quad g_{j} \wedge g_{k}=0$ for $j<k$.

Proof. By 2.1, $M$ is not equicontinuous on $\operatorname{Lip}(h)$ at 0 . Every $f \in \operatorname{Lip}(h)$ may be written as $f=f^{+}-f^{-}$with $f^{+}, f^{-} \in \operatorname{Lip}^{+}(h)$, and $\mathrm{Sm}(h)$ is dense in $\operatorname{Lip}^{+}(h)$. Hence $M$ is not equicontinuous on $\mathrm{Sm}(h)$ at 0 : there is a $\gamma>0$ such that

$$
\forall \delta>0 \forall F \in \operatorname{Fin}(X) \exists f \in \operatorname{Sm}(h) \exists \mu \in M:\|f\|_{F}<\delta \text { and }|\mu(f)|>3 \gamma .
$$

Take such a $\gamma>0$ and keep it fixed through the whole proof. To reduce the number of quantifiers, we drop $\delta$ : Put $\delta=\gamma / t$ and $g=$ $(f-\delta)^{+}$to get

(1) $\forall F \in \operatorname{Fin}(X) \exists g \in \operatorname{Sm}(h) \exists \mu \in M:\|g\|_{F}=0$ and $|\mu(g)|>2 \gamma$.

Now we distinguish two cases. Case II can arise only when $h$ is unbounded.

Case I. Assume that there is a $r \geqq 0$ such that for all $\mu \in M$ and $f \in \operatorname{Sm}(h)$ we have $|\mu(f-f \wedge r)| \leqq \gamma$. (This is automatically satisfied when $h$ is bounded.) Substituting this to (1) we get

(2) $\forall F \in \operatorname{Fin}(X) \exists g \in \operatorname{Sm}(h) \exists \mu \in M:\|g\| \leqq r,\|g\|_{F}=0$ and $|\mu(g)|>\gamma$. 
For $n=1,2, \cdots$ consider the statement

$\left(\mathscr{S}_{n}\right) \forall F \in \operatorname{Fin}(X) \exists g \in \operatorname{Sm}(h) \exists \mu \in M:\|g\| \leqq r / 2^{n-1}, \quad\|g\|_{F}=0$ and

$$
|\mu(g)|>\left(\frac{1}{2}+\frac{1}{2 n}\right) \gamma \text {. }
$$

Plainly $\left(\mathscr{S}_{n}\right)$ does not hold for $2^{n} \geqq 4 r t / \gamma$; on the other hand, $\left(\mathscr{S}_{1}\right)$ does hold by (2). Choose $n$ such that $\left(\mathscr{S}_{n}\right)$ is true and $\left(\mathscr{S}_{n+1}\right)$ is not. With $\eta=r / 2^{n}, \gamma^{*}=(1 / 2+1 / 2 n) \gamma$ and $\varepsilon=\gamma / 4 n(n+1)$ we have

$$
\begin{gathered}
\forall F \in \operatorname{Fin}(X) \exists g \in \operatorname{Sm}(h) \exists \mu \in M:\|g\| \leqq 2 \eta, \quad\|g\|_{F}=0 \text { and } \\
|\mu(g)|>\gamma^{*},
\end{gathered}
$$$$
\exists F_{0} \in \operatorname{Fin}(X) \forall g \in \operatorname{Lip}(h) \forall \mu \in M:\left[0 \leqq g \leqq \eta,\|g\|_{F_{0}}=0\right]
$$

$$
\Rightarrow|\mu(g)| \leqq \gamma^{*}-2 \varepsilon \text {. }
$$

(The negation of $\left(\mathscr{S}_{n+1}\right)$ gives only $\exists F_{0} \forall g \in \operatorname{Sm}(h) \cdots$; however, $\{g \in \operatorname{Sm}(h) \mid g \leqq \eta\}$ is dense in $\{g \in \operatorname{Lip}(h) \mid 0 \leqq g \leqq \eta\}$. Hence (4) follows.)

We are going to construct $g_{k}^{*} \in \operatorname{Sm}(h)$ and $\mu_{k} \in M$ for $k=1,2, \cdots$ such that

$1^{00} . \quad\left\|g_{k}^{*}\right\| \leqq 2 \eta$ and $\left|\mu_{k}\left(g_{k}^{*}\right)\right|>\gamma^{*}$,

$2^{00} . \quad\left|\mu_{j}\left(g_{k}^{*}-g_{k}^{*} \wedge \eta\right)\right| \leqq \varepsilon$ for $j<k$, and

$3^{00} . \quad g_{j}^{*} \wedge g_{k}^{*} \leqq \eta$ for $j<k$.

First use (3) to find $g_{1}^{*} \in \operatorname{Sm}(h)$ and $\mu_{1} \in M$ such that $\left\|g_{1}^{*}\right\| \leqq 2 \eta$ and $\left|\mu_{1}\left(g_{1}^{*}\right)\right|>\gamma^{*}$ (conditions $2^{00}$ and $3^{00}$ are empty for $k=1$ ). For $k \geqq 2$, when $\mu_{j}$ and $g_{j}^{*}$ have been constructed for $j<k$, take a finite set $F \subset X$ such that $F \supset F_{0}, F \supset F\left(g_{j}^{*}\right)$ for $j<k$, and $\left|\mu_{j}(f)\right| \leqq \varepsilon$ whenever $f \in \operatorname{Lip}(h),\|f\|_{F}=0$ and $j<k$. Use (3) to get a $g_{k}^{*} \in \operatorname{Sm}(h)$ and a $\mu_{k} \in M$ such that $\left\|g_{k}^{*}\right\| \leqq 2 \eta,\left\|g_{k}^{*}\right\|_{F}=0$ and $\left|\mu_{k}\left(g_{k}^{*}\right)\right|>\gamma^{*}$. Conditions $1^{00}$ and $2^{00}$ are obviously satisfied. As for $3^{00}$, put $f^{*}=$ $\left(2 \eta-g_{k}^{*}\right)^{+} \wedge h$; then $f^{*} \in \operatorname{Lip}^{+}(h)$ and for $y \in F, j<k$ we have $f^{*}(y)=$ $2 \eta \wedge h \geqq g_{j}^{*}(y)$. This together with $F \supset F\left(g_{j}^{*}\right)$ gives $f^{*} \geqq g_{j}^{*}$. Now, if $g_{k}^{*}(x)>\eta$ for some $x \in X$ then $\eta>f^{*}(x) \geqq g_{j}^{*}(x)$; hence $g_{j}^{*} \wedge g_{k}^{*} \leqq \eta$.

Finally, put $g_{k}=g_{k}^{*}-g_{k}^{*} \wedge \eta$. Conditions $2^{0}, 3^{0}$ follow from $2^{00}$, $3^{00}$. As for $1^{0}$, we have

$$
\left|\mu_{k}\left(g_{k}\right)\right| \geqq\left|\mu_{k}\left(g_{k}^{*}\right)\right|-\left|\mu_{k}\left(g_{k}^{*} \wedge \eta\right)\right|>\gamma^{*}-\left(\gamma^{*}-2 \varepsilon\right)=2 \varepsilon,
$$

by (4).

This concludes the proof when $h$ is bounded. In the general case we have to consider one more possibility:

Case II. Assume that the assumption made in Case I does not hold. Thus for every $r \geqq 0$ there are a $\mu \in M$ and an $f \in \operatorname{Sm}(h)$ such that $|\mu(f-f \wedge r)|>\gamma$. Put $\varepsilon=\gamma / 2$. 
Choose $\mu_{1} \in M$ and $g_{1} \in \operatorname{Sm}(h)$ such that $\left|\mu_{1}\left(g_{1}\right)\right|>2 \varepsilon$. For $k \geqq 2$, when $\mu_{j}$ and $g_{j}$ have been constructed for $j<k$, take a finite set $F \subset X$ such that $F \supset F\left(g_{j}\right)$ for $j<k$ and $\left|\mu_{j}(f)\right| \leqq \varepsilon$ whenever $j<k$, $f \in \operatorname{Lip}(h)$ and $\|f\|_{F}=0$. Put $r_{k}=2 \max \{h(y) \mid y \in F\}$ and use the assumption to produce a $\mu_{k} \in M$ and an $f_{k} \in \operatorname{Sm}(h)$ with $\left|\mu_{k}\left(f_{k}-f_{k} \wedge r_{k}\right)\right|>$ 2ع. Put $g_{k}=f_{k}-f_{k} \wedge r_{k}$; condition $1^{0}$ is satisfied. We have $f_{k}(y) \leqq$ $h(y) \leqq r_{k}$ for each $y \in F$, hence $g_{k}(y)=0$. Thus $\left\|g_{k}\right\|_{F}=0$ and $2^{0}$ follows.

Finally, put $f^{*}=\left(r_{k}-f_{k}\right)^{+} \wedge h$. Then $f^{*} \in \operatorname{Lip}^{+}(h)$, and for $y \in F$, $j<k$, we have

$$
f^{*}(y) \geqq\left(r_{k}-f_{k}(y)\right) \wedge h(y) \geqq\left(r_{k}-h(y)\right) \wedge h(y) \geqq h(y) \geqq g_{j}(y) .
$$

This along with $F \supset F\left(g_{j}\right)$ implies $f^{*} \geqq g_{j}$. If $x \in X$ and $g_{k}(x)>0$ then $f_{k}(x)>r_{k}$, hence $f^{*}(x)=0$; this proves $3^{0}$, for $g_{k} \wedge g_{j} \leqq g_{k} \wedge$ $f^{*}=0$.

COROLlaRY 2.3 Let $M \subset \mathfrak{M}$ and suppose that there is a $t>0$ such that $|\mu(f)| \leqq t\|f\|$ for any $\mu \in M$ and any bounded $f \in U$. If $M$ is not $\|\cdot\|_{d, h}$-precompact then there is a continuous linear map $p$ : $\mathfrak{M} \rightarrow l^{1}$ such that $p(M) \subset l^{1}$ is not norm-precompact.

Proof. Produce $\mu_{k}$ and $g_{k}$ as in 2.2, satisfying $1^{\circ}, 2^{\circ}$ and $3^{\circ}$. Define a linear $\operatorname{map} q: l^{\infty} \rightarrow U$ by

$$
q\left(\left\{z_{k}\right\}_{k=1}^{\infty}\right)=\sum_{k=1}^{\infty} z_{k} g_{k}
$$

for every bounded real sequence $\left\{z_{k}\right\}_{k=1}^{\infty}$. Since the functions $g_{k}$ are pairwise disjoint, the sum is well defined and, moreover, $q(z) \in 2 \operatorname{Lip}(h)$ whenever $z$ is in the unit ball of $l^{\infty}$. It follows that the transposed map $p={ }^{t} q$ maps $\mathfrak{M}$ into $l^{1}$ and is continuous, with $\|p\| \leqq 2$. In order to show that $p(M)$ is not precompact in $l^{1}$, we prove that the infinite set $\left\{p\left(\mu_{k}\right) \mid k=1,2, \cdots\right\}$ is norm-discrete:

$$
\begin{aligned}
\left\|p\left(\mu_{j}\right)-p\left(\mu_{k}\right)\right\| & =\sup \left\{\left|\left\langle p\left(\mu_{j}\right)-p\left(\mu_{k}\right), z\right\rangle\right| \mid z \in l^{\infty},\|z\| \leqq 1\right\} \\
& =\sup \left\{\left|\left\langle\mu_{j}-\mu_{k}, q(z)\right\rangle\right| \mid z \in l^{\infty},\|z\| \leqq 1\right\} \\
& \geqq\left|\mu_{j}\left(g_{k}\right)-\mu_{k}\left(g_{k}\right)\right|>\varepsilon
\end{aligned}
$$

for $j<k$.

3. Results. Corollary 2.3 allows us to deduce the properties of $\mathfrak{M}_{t}(X)$ from those of $l^{1}$. Let us recall the relevant facts about $l^{1}$ :

THEOREM 3.1. (a) The space $l^{1}$ is weakly sequentially complete. (b) Every weakly convergent sequence in $l^{1}$ is norm convergent. 
Hence every weakly countably compact set in $l^{1}$ is norm-compact.

Proof is in ([2], II- $\S 2)$. The second assertion in (b) uses the theorem of Eberlein ([2], III- $\S 2)$.

Let $X$ be a complete metric space and $h$ a Lipschitz function on $X$. The compact-open topology and the topology of pointwise convergence agree on $\operatorname{Lip}(h)$; this is the only topology on $\operatorname{Lip}(h)$ we consider. It is well known (see e.g., [4], [7]) that a bounded Radon measure on $X$ can be characterized as a linear form on $\mathscr{U}_{b}(X)$ which is $\|\cdot\|$-continuous and whose restriction to $\operatorname{Lip}(1)$ is continuous.

Define again the norm $\|\cdot\|_{d}=\|\cdot\|_{d, 1}$ on $\mathfrak{M}_{t}(X)$ by

$$
\|\mu\|_{d}=\sup \{|\mu(f)| \mid f \in \operatorname{Lip}(1)\} \text {. }
$$

THEOREM 3.2. Let $X$ be a complete metric space. (a) The space $\mathfrak{M}_{t}(X)$ is $w\left(\mathfrak{M}_{t}, \mathscr{U}_{b}\right)$ sequentially complete.

(b) Let a set $M \subset \mathfrak{M}_{t}(X)$ be bounded on the unit $\|\cdot\|$-ball in $\mathscr{Q}_{b}(X)$. The following conditions are equivalent:

(i) $M$ is relatively $\|\cdot\|_{d^{-}}$compact;

(ii) $M$ is relatively $w\left(\mathfrak{M}_{t}, \mathscr{U}_{b}\right)$ countably compact;

(iii) The restriction of $M$ to $\operatorname{Lip}(1)$ is equicontinuous.

Proof. (a) Suppose that $\left\{\mu_{n}\right\}_{n=1}^{\infty}$ is a $w\left(\mathfrak{M}_{t}, \mathscr{C}_{b}\right)$ Cauchy sequence and $\left\{\mu_{n} \mid n=1,2, \cdots\right\}$ is not $\|\cdot\|_{d}$-precompact. The sequence is bounded on the unit $\|\cdot\|$-ball in $\mathscr{U}_{b}(X)$ by the Banach-Steinhaus theorem, and 2.3 produces a $p: \mathfrak{M}_{t} \rightarrow l^{1}$ such that $\left\{p\left(\mu_{n}\right) \mid n=1,2, \cdots\right\} \subset l^{1}$ is not precompact. As the sequence $\left\{p\left(\mu_{n}\right)\right\}_{n=1}^{\infty}$ is $w\left(l^{1}, l^{\infty}\right)$ Cauchy, this contradicts 3.1. Hence $\left\{\mu_{n} \mid n=1,2, \cdots\right\}$ is $\|\cdot\|_{d}$-precompact. It follows that the $w\left(\mathscr{U}_{b}^{*}, \mathscr{U}_{b}\right)$ limit of the sequence (in the algebraic dual $\mathscr{U}_{b}^{*}$ of $\left.\mathscr{U}_{b}\right)$ is both $\|\cdot\|_{X}$-continuous on $\mathscr{C}_{b}$ and continuous on Lip (1), i.e., belongs to $\mathfrak{M}_{t}$.

(b) Obviously (i) $\Leftrightarrow$ (iii) and (i) $\Rightarrow$ (ii). If $M$ is relatively $w\left(\mathfrak{M}_{t}, \mathscr{C}_{b}\right)$ countably compact but not $\|\cdot\|_{d}$-precompact, then there is, again by 2.3, a $p: \mathfrak{M}_{t} \rightarrow l^{1}$ such that $p(M)$ is relatively $w\left(l^{1}, l^{\infty}\right)$ countably compact but not norm-precompact. This contradiction proves the implication (ii) $\Rightarrow$ (i).

Now let $X$ be a uniform space. The uniform structure of $X$ is projectively generated by uniformly continuous maps into complete metric spaces; the $U E B$-topology in the space $\mathfrak{M}_{u}(X)$ is generated by the corresponding maps into the spaces of Radon measures ([4], [5]).

CoRollary 3.3. Let $X$ be a uniform space. (a) The space $\mathfrak{M}_{u}(X)$ is $w\left(\mathfrak{M}_{u}, \mathscr{U}_{b}\right)$ sequentially complete.

(b) The following properties of a set $M \subset \mathfrak{M}_{u}(X)$ are equivalent: 
(i) $M$ is relatively UEB-compact;

(ii) $M$ is relatively $w\left(\mathfrak{M}_{u}, \mathscr{U}_{b}\right)$ countably compact;

(iii) The restriction of $M$ to any UEB set is equicontinuous.

Proof. (a) follows immdiately from 3.2(a). In order to deduce (b) from $3.2(\mathrm{~b})$, it is enough to realize that every $w\left(\mathfrak{M}_{u}, \mathscr{C}_{b}\right)$ bounded set is $U E B$-bounded and also bounded on the unit $\|\cdot\|$-ball in $\mathscr{C}_{b}(X)$.

Thus the $U E B$-topology agrees with $w\left(\mathfrak{M}_{u}, \mathscr{\mathscr { C }}_{b}\right)$ on every relatively $w\left(\mathfrak{M}_{u}, \mathscr{C}_{b}\right)$ countably compact subset of $\mathfrak{M}_{u}(X)$. LeCam [7] proved that the two topologies agree on the positive cone $\mathfrak{M}_{u}^{+}(X)$.

In the same way as the sets $\operatorname{Lip}(1)$ generate the $U E B$-topology in $\mathfrak{M}_{u}(X)$, the general sets $\operatorname{Lip}(h)$ generate the $U E$-topology in the space $\mathfrak{M}_{F}(X)$ of free uniform measures [8]. Thus 2.3 yields the following analogue to 3.3 .

Proposition 3.4. Let $X$ be a uniform space. (a) The space $\mathfrak{M}_{F}(X)$ is $w\left(\mathfrak{M}_{F}, \mathscr{U}\right)$ sequentially complete.

(b) The following properties of a set $M \subset \mathfrak{M}_{F}(X)$ are equivalent:

(i) $M$ is relatively UE-compact;

(ii) $M$ is relatively $w\left(\mathfrak{M}_{F}, \mathscr{U}\right)$ countably compact;

(iii) The restriction of $M$ to any $U E$ set is equicontinuous.

\section{REFERENCES}

1. J. B. Conway, A theorem on sequential convergence of measures and some applications, Pacific J. Math., 28 (1969), 53-60.

2. M. M. Day, Normed linear spaces, 2nd Edition, New York 1962.

3. R. M. Dudley, Convergence of Baire measures, Studia Math., 27 (1966), 251-268. Correction: Studia Math., 51 (1974), 275.

4. Z. Frolik, Measure-fine uniform spaces I, Lecture Notes in Mathematics No. 541, 403-413; Springer-Verlag 1976.

5. Z. Frolík, J. Pachl and M. Zahradník, Examples of uniform measures, Proc. Conf. "Topology and Measure" (Zinnowitz 1974), Ernst-Moritz-Arndt-Universität Greifswald 1978.

6. J. L. Kelley, General Topology, Princeton 1955.

7. L. Le Cam, Note on a certain class of measures, unpublished.

8. J. Pachl, Free uniform measures on sub-inversion-closed spaces, Comment. Math. Univ. Carolinae, 17 (1976), 291-306.

9. Compactness in spaces of uniform measures, Comment. Math. Univ. Carolinae, 16 (1975), 795-797.

10. M. Rome, L'espace $M^{\infty}(T)$, Publ. Dépt. Math. (Lyon) 9-1 (1972), 37-60.

11. F. D. Sentilles, Bounded continuous functions on a completely regular space, Trans. Amer. Math. Soc., 168 (1972), 311-336.

12. F. D. Sentilles and R. F. Wheeler, Linear functionals and partitions of unity in $C_{b}(X)$, Duke Math. J., 41 (1974), 483-496.

13. M. Zahradník, $l_{1}$-continuous partitions of unity, Czechoslovak Math. J., 26 (1976), 319-329.

Received April 12, 1978. Research supported in part by National Research Council of Canada.

UNIVERSITY OF BRITISH COLUMBIA

VANCOUver, B. C., CANADA V6T 1W5 



\section{PACIFIC JOURNAL OF MATHEMATICS}

\section{EDITORS}

Donald BABBITT (Managing Editor)

University of California

Los Angeles, CA 90024

HUGo RossI

University of Utah

Salt Lake City, UT 84112

C. C. MOORE and ANDREW OGG

University of California

Berkeley, CA 94720

\section{J. DuGUNDJI}

Department of Mathematics

University of Southern California

Los Angeles, CA 90007

R. FINN and J. Milgram

Stanford University

Stanford, CA 94305

ASSOCIATE EDITORS
E. F. BECKENBACH
B. H. NeumanN
F. WOLF
K. YoSHIDA

\section{SUPPORTING INSTITUTIONS}

\author{
UNIVERSITY OF BRITISH COLUMBIA \\ CALIFORNIA INSTITUTE OF TECHNOLOGY \\ UNIVERSITY OF CALIFORNIA \\ MONTANA STATE UNIVERSITY \\ UNIVERSITY OF NEVADA, RENO \\ NEW MEXICO STATE UNIVERSITY \\ OREGON STATE UNIVERSITY \\ UNIVERSITY OF OREGON
}

\author{
UNIVERSITY OF SOUTHERN CALIFORNIA \\ STANFORD UNIVERSITY \\ UNIVERSITY OF HAWAII \\ UNIVERSITY OF TOKYO \\ UNIVERSITY OF UTAH \\ WASHINGTON STATE UNIVERSITY \\ UNIVERSITY OF WASHINGTON
}

The Supporting Institutions listed above contribute to the cost of publication of this Journal, but they are not owners or publishers and have no responsibility for its content or policies.

Mathematical papers intended for publication in the Pacific Journal of Mathematics should be in typed form or offset-reproduced, (not dittoed), double spaced with large margins. Please do not use built up fractions in the text of the manuscript. However, you may use them in the displayed equations. Underline Greek letters in red, German in green, and script in blue. The first paragraph or two must be capable of being used separately as a synopsis of the entire paper. Please propose a heading for the odd numbered pages of less than 35 characters. Manuscripts, in triplicate, may be sent to any one of the editors. Please classify according to the scheme of Math. Reviews, Index to Vol. 39. Supply name and address of author to whom proofs should be sent. All other communications should be addressed to the managing editor, or Elaine Barth, University of California, Los Angeles, California, 90024.

50 reprints to each author are provided free for each article, only if page charges have been substantially paid. Additional copies may be obtained at cost in multiples of 50 .

The Pacific Journal of Mathematics is issued monthly as of January 1966. Regular subscription rate: $\$ 84.00$ a year (6 Vols., 12 issues). Special rate: $\$ 42.00$ a year to individual members of supporting institutions.

Subscriptions, orders for numbers issued in the last three calendar years, and changes of address should be sent to Pacific Journal of Mathematics, P.O. Box 969, Carmel Valley, CA 93924, U.S.A. Older back numbers obtainable from Kraus Periodicals Co., Route 100, Millwood, NY 10546.

PUBLISHED BY PACIFIC JOURNAL OF MATHEMATICS, A NON-PROFIT CORPORATION

Printed at Kokusai Bunken Insatsusha (International Academic Printing Co., Ltd.). 8-8, 3-chome, Takadanobaba, Shinjuku-ku, Tokyo 160, Japan.

Copyright (C) 1979 by Pacific Journal of Mathematics Manufactured and first issued in Japan 


\section{Pacific Journal of Mathematics}

\section{Vol. 82 , No. 2 \\ February, 1979}

Krishnaswami Alladi and Paul Erdős, On the asymptotic behavior of large prime

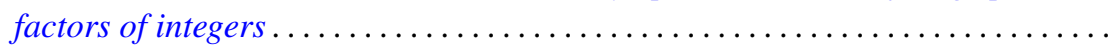

Alfred David Andrew, A remark on generalized Haar systems in $L_{p}$,

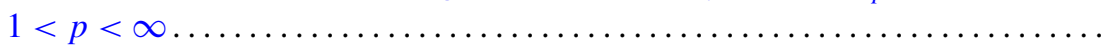

John M. Baker, A note on compact operators which attain their norm . . ........

Jonathan Borwein, Weak local supportability and applications to

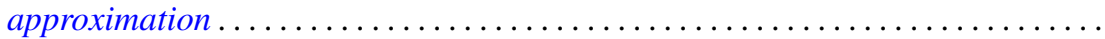

Tae Ho Choe and Young Soo Park, Wallman's type order compactification ........

Susanne Dierolf and Ulrich Schwanengel, Examples of locally compact

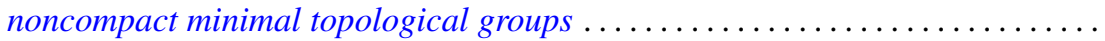

Michael Freedman, A converse to (Milnor-Kervaire theorem) $\times R$ etc. . . . . . . .

George Golightly, Graph-dense linear transformations ..................

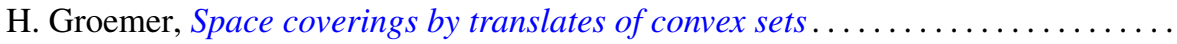

Rolf Wim Henrichs, Weak Frobenius reciprocity and compactness conditions in

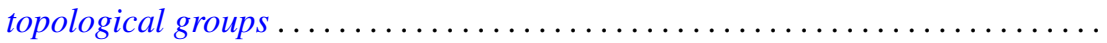

Horst Herrlich and George Edison Strecker, Semi-universal maps and universal

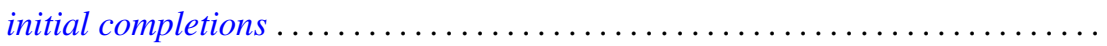

Sigmund Nyrop Hudson, On the topology and geometry of arcwise connected,

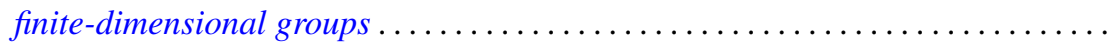

K. John and Václav E. Zizler, On extension of rotund norms. II .............

Russell Allan Johnson, Existence of a strong lifting commuting group of transformations. II.

Bjarni Jónsson and Ivan Rival, Lattice varieties covering the smallest nonmodular variety

Grigori Abramovich Kolesnik, On the order of Dirichlet L-functions .

Robert Allen Liebler and Jay Edward Yellen, In search of nonsolvable groups of

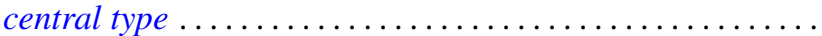

Wilfrido Martínez T. and Adalberto Garcia-Maynez Cervantes, Unicoherent plane Peano sets are $\sigma$-unicoherent ...

M. A. McKiernan, General Pexider equations. I. Existence of injective

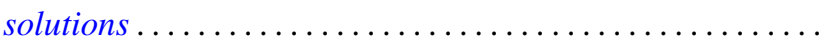

M. A. McKiernan, General Pexider equations. II. An application of the theory of webs.

Jan K. Pachl, Measures as functionals on uniformly continuous functions . .

Lee Albert Rubel, Convolution cut-down in some radical convolution algebras ...

Peter John Slater and William Yslas Vélez, Permutations of the positive integers

with restrictions on the sequence of differences. II . . .

Raymond Earl Smithson, A common fixed point theorem for nested spaces ....

Indulata Sukla, Generalization of a theorem of McFadden .... . . .

Jun-ichi Tanaka, A certain class of total variation measures of analytic measures.

Kalathoor Varadarajan, Modules with supplements .............. 